\title{
Renal Na-K-ATPase hyperactivity in diabetic Psammomys obesus is related to glomerular hyperfiltration but is insulin-independent
}

\author{
P Scherzer, I Nachliel ${ }^{1}$, H Bar-On ${ }^{1}$, M M Popovtzer and E Ziv ${ }^{1}$ \\ Nephrology and Hypertension Services, Hadassah University Hospital, Jerusalem, Israel \\ ${ }^{1}$ Diabetes Unit, Hadassah University Hospital, Jerusalem, Israel \\ (Requests for offprints should be addressed to M Popovtzer, Nephrology and Hypertension Services, Hadassah University Hospital, POB 12000, \\ Jerusalem 91120, Israel; Email: popovtzer@hadassah.org.il)
}

\begin{abstract}
Psammomys obesus, a desert rodent, develops diabetes when displaced from its natural environment and fed a high energy diet in the laboratory. This study was designed to examine variations in renal function in relation to the diabetic state with emphasis on changes in Na-K-ATPase activity.

The following groups of Psammomys were studied: (1) Animals fed a saltbush diet; a low energy/high salt diet (natural). (2) Animals fed a low energy/low salt diet (laboratory). Both 1 and 2 were normoglycemic and normoinsulinemic and thus served as control. (3) Animals fed a high energy diet (group C) who were hyperglycemic and hyperinsulinemic; this group was divided into two subgroups: C1 presented with glomerular hyperfiltration rate and C2 with glomerular hypofiltration rate. (4) Animals fed a high energy diet presenting with hyperglycemia-hypoinsulinemia (group D). (5) Group D+I, similar to group D but treated with external insulin (2 U/24 h).

Groups D and C1, whose glomerular filtration rose above normal by $30 \%$ and $70 \%$ respectively, exhibited
\end{abstract}

metabolic similarity to Type I and Type II diabetes. In these groups, Na-K-ATPase activity in the cortex increased by $80-100 \%$ and in the medulla by $180 \%$ $(P<0 \cdot 001$ vs control). In group C2 with reduced glomerular filtration rate (GFR), Na-K-ATPase activity did not differ from control. In group $\mathrm{D}+\mathrm{I}$, with normalized glomerular filtration rate, Na-K-ATPase activity was similar to control. There was a linear and significant correlation between GFR and Na-K-ATPase activity both in the cortex and in the medulla.

These experiments present a well defined animal model of diabetes mellitus. Variations in glucose and in insulin did not correlate with Na-K-ATPase activity. These results clearly demonstrated that Na-K-ATPase activity in the diabetic Psammomys was determined by glomerular filtration but was independent of plasma glucose or insulin levels.

Journal of Endocrinology (2000) 167, 347-354

\section{Introduction}

Psammomys obesus is prone to develop obesity, hyperglycemia and hyperinsulinemia when fed a high energy (HE) diet $(2.93 \mathrm{kcal} / \mathrm{g})$ (Kalman et al. 1993). In nature the Psammomys is a herbivorous rodent, subsisting on a low energy, high salt diet. In the Israeli desert the Psammomys feeds mainly or solely on saltbush (Atriplex halimus). We have isolated two defined genetic lines of the Psammomys: a diabetic prone (DP) line and a diabetes resistant (DR) line (Ziv \& Shafrir 1995). The selection process was done in laboratory by feeding the animals the HE diet. The diabetic state that develops can be prevented, and/or reversed by feeding the animals LE diet $(2 \cdot 3 \mathrm{kcal} / \mathrm{g})$. The development of diabetes and obesity can be understood by the 'thrifty metabolism' theory. Our findings show that the Psammomys behaves according to this theory. The animals of the DP line use the food components more efficiently than the animals of the DR line (by 50\%) (Kalman et al.
1993). It leads to the intensive and continuous storage of fat, and to obesity in the DP animals. Primary insulin resistance in Psammomys is an innate species characteristic that enables the animals to survive and breed in its natural low energy habitat ( $\mathrm{Ziv}$ et al. 1996). Insulin resistance becomes a disadvantage when Psammomys is continuously fed a HE diet. A prolonged state of hyperglycemia leads to several secondary complications in the Psammomys model, such as nephropathy and kidney failure.

$\mathrm{Na}-\mathrm{K}-\mathrm{ATP}$ ase, the enzyme that is responsible for the active transport of sodium and potassium (Skou 1965), is present in high concentrations in the kidney (Schmidt \& Dubach 1969). It has been implicated in the process of active reabsorption of sodium from the glomerular filtrate by renal tubules (Katz \& Epstein 1967). In a previous study from our laboratory (Wald et al. 1983), evidence was presented to support the concept that the kidney responds to chronic changes in the filtered load of sodium with an adaptive increase in the specific activity of the transport 
Table 1 Different experimental Psammomys groups

\begin{tabular}{|c|c|c|c|c|c|c|}
\hline & $\begin{array}{l}\text { No. of } \\
\text { animals }\end{array}$ & $\begin{array}{l}\text { Digestible } \\
\text { energy }(\mathrm{kcal} / \mathrm{g})\end{array}$ & Type of diabetes & $\begin{array}{l}\text { Blood glucose } \\
\text { after fast }\end{array}$ & $\begin{array}{l}\text { Blood glucose } \\
\text { after food }\end{array}$ & Insulin levels \\
\hline \multicolumn{7}{|l|}{ Group } \\
\hline Saltbush diet (SB) & 11 & $1 \cdot 92$ & - & Normal & Normal & Normal \\
\hline $\begin{array}{l}\text { High energy diet (HE). } \\
\text { Group C }\end{array}$ & 24 & $2 \cdot 93$ & Type II & Normal & High & High \\
\hline $\begin{array}{l}\text { High energy diet (HE) } \\
\quad+\text { insulin } 2 \mathrm{U} / 24 \mathrm{~h} \text {. Group } \mathrm{D}+\mathrm{I}\end{array}$ & 8 & $2 \cdot 93$ & Type II & Normal & High & High \\
\hline
\end{tabular}

enzyme $\mathrm{Na}-\mathrm{K}$-ATPase. A remarkable increase in the glomerular filtration rate (GFR) has been observed in the early stage of streptozotocin-induced diabetes mellitus in the rat (Canney et al. 1979, Wald \& Popovtzer 1984). The increase in GFR was accompanied by a commensurate increase in the filtered load of sodium.

In a previous publication (Wald et al. 1993), we examined the effect of long-term diabetes on rat $\mathrm{Na}-\mathrm{K}$ ATPase activity in individual nephron segments and the effect of insulin treatment on that activity. In rat, after the induction of diabetes mellitus with streptozotocin (STPZDM), GFR rose and Na-K-ATPase activity increased in all nephron segments studied. Partial correction of blood glucose with external insulin replacement $(2 \mathrm{U} / 24 \mathrm{~h})$ led to a decrease in $\mathrm{Na}-\mathrm{K}-\mathrm{ATP}$ ase in the proximal tubules and distal convoluted tubules, while partial correction of blood glucose in the presence of elevated GFR did not alter the $\mathrm{Na}-\mathrm{K}-\mathrm{ATP}$ ase activity in the loop of Henle.

In general, the first stage of insulin-dependent diabetes mellitus (Type I, IDDM) is characterized by glycosuria and natriuresis, followed by increase in Na-K-ATPase activity in the proximal convoluted and proximal straight tubules. Subsequently, during the diabetic state, there is an increase in GFR and $\mathrm{Na}-\mathrm{K}$-ATPase activity of the thick ascending limb of Henle's loop.

In non-insulin-dependent diabetes mellitus (Type II, NIDDM), which is characterized by high blood glucose levels after food intake, the plasma insulin levels can vary from normal or high to low in long-term diabetes.

It was of interest in this context to characterize and to study the kidney function in the diabetic state of the Psammomys from the diabetic prone line. The transition of Psammomys to diabetes has been classified by Kalderon et al. (1986) into four consecutive states: A: normoinsulinemia and normoglycemia; B: hyperinsulinemia and normoglycemia, C: hyperinsulinemia and hyperglycemia, and D: hyperglycemia and hypoinsulinemia, due to loss of beta-cell insulin secretory capacity. The progression of the nutritionally induced diabetes in Psammomys in many respects resembles the development of the hyperglycemichyperinsulinemic stage in human populations. The investigation of the primary insulin resistance and the secondary complications that develop in the diabetic Psammomys may provide better understanding of Type II diabetes mellitus in the human population.

The present study was undertaken to further characterize (a) the renal function and $\mathrm{Na}-\mathrm{K}$-ATPase activity in the kidney of the diabetic Psammomys from the diabetic prone line, and (b) the effect of varying severity of glycemic abnormality and insulin levels in the Psammomys on above measurements.

\section{Materials and Methods}

The animal experiments were approved by the Institutional Animal Welfare Committee.

Male Psammomys obesus (sand rat) of the Hebrew University strain were used in all the experiments. The animals were weaned at 3 weeks of age to one of the following groups (Table 1).

(1) Normoglycemic, normoinsulinemic Psammomys fed its native diet, the saltbush (SB; Atriplex halimus) leaves, picked from their natural habitat, the Dead Sea area. This group is equal to low energy, high salt diet and represents the basic natural state of Psammomys (SB group). The $\mathrm{Na}$ content in the saltbush leaves is $61.7 \pm 2 \cdot 1 \mathrm{mg} / \mathrm{g}$ dry matter and the $\mathrm{K}$ content $36 \pm 7.7 \mathrm{mg} / \mathrm{g}$ dry matter (Degen 1988).

(2) Normoglycemic, normoinsulinemic Psammomys fed artificial commercial, low energy, low salt laboratory diet (LE group) (Koffolk, Tel Aviv, Israel). The Na content is $2.4 \mathrm{mg} / \mathrm{g}$ dry matter, and the $\mathrm{K}$ content $14.6 \mathrm{mg} / \mathrm{g}$ dry matter. The composition of the diets is given in Table 2 .

(3) Hyperglycemic, hyperinsulinemic Psammomys fed for 5 weeks from weaning with commercial laboratory high energy (HE) diet $(2.93 \mathrm{kcal} / \mathrm{g})$ (Table 2) (Koffolk). The $\mathrm{Na}$ content is $2.4 \mathrm{mg} / \mathrm{g}$ dry matter and $\mathrm{K}$ content $14.6 \mathrm{mg} / \mathrm{g}$ dry matter (Kalman et al. 1993). In this group the glucose level was normal in fasted state and high (>200 mg/dl) following food intake (group C) (Kalderon et al. 1986). This group of animals was used as a model of Type II diabetes mellitus. 
Table 2 Composition of the saltbush native (SB), low energy (LE) and high energy (HE) diets

\begin{tabular}{|c|c|c|c|}
\hline & SB & LE & HE \\
\hline \multicolumn{4}{|l|}{ Dietary } \\
\hline Protein \% & $23 \cdot 3$ & $16 \cdot 2$ & $23 \cdot 6$ \\
\hline Fat $\%$ & $2 \cdot 9$ & $3 \cdot 1$ & $2 \cdot 4$ \\
\hline Carbohydrate \% & $53 \cdot 3$ & $70 \cdot 0$ & 68 \\
\hline $\mathrm{NaCl} \%$ & $8 \cdot 0$ & $1 \cdot 1$ & $1 \cdot 1$ \\
\hline Ash \% & $12 \cdot 5$ & $9 \cdot 6$ & $5 \cdot 0$ \\
\hline Digestible energy (kcal/g) & $1 \cdot 92$ & $2 \cdot 38$ & $2 \cdot 93$ \\
\hline
\end{tabular}

(4) Hyperglycemic, hypoinsulinemic Psammomys fed HE diet for 8 weeks. Their blood glucose was high $(>300 \mathrm{mg} / \mathrm{dl})$ even after overnight fasting and after food intake. This group of animals was used as a model of Type I diabetes mellitus (group D). These animals, after developing a hypoinsulinemic state, survived for only several days.

(5) Hyperglycemic hyperinsulinemic Psammomys fed HE diet for 8 weeks, similar to group D but on the day following appearance of hyperglycemia (at the fasting state) an insulin release tablet $(2 \mathrm{U} / 24 \mathrm{~h})$ was implanted subcutaneously for one additional week (group D + I) (Wang 1989). Following this procedure the animals became normoglycemic at the fasted state (similar to group C).

Blood glucose and insulin levels were monitored weekly for 3-9 weeks. Blood was drawn from the tail vein after fasting and after food intake. At the end of the experimental period (each group in their suitable time), the animals were housed in individual polypropylene cages for kidney function determinations. Urine collection was performed for $24 \mathrm{~h}$. The Psammomys were fed their respective diet (SB, LE or HE) and allowed to drink water ad libitum.

At the end of the experimental period blood was drawn from the aorta under ether anesthesia and the animals were killed. The kidneys were removed immediately, decapsulated, weighed and kept on ice. Slices of cortex and outer medulla were cut and stored separately for preparation of microsomal ATPase.

\section{Preparation of microsomes}

Preparation of microsomal ATPase was carried out according to Jørgensen \& Skou (1969). The tissues from two kidneys of each individual animal in the experimental and control groups, at least six animals, were homogenized in 10 volumes of medium containing $0.25 \mathrm{~mol} / 1$ sucrose, and $2 \mathrm{mmol} / \mathrm{l}$ EDTA buffered with $5 \mathrm{mmol} / \mathrm{l}$ Tris $-\mathrm{HCl}$ to a $\mathrm{pH}$ of $7 \cdot 4-7 \cdot 5$. The homogenate was centrifuged at $7000 \mathrm{~g}$ for $15 \mathrm{~min}$; the supernatant was decanted and the sediment centrifuged at $48000 \mathrm{~g}$ for $40 \mathrm{~min}$. The pellet was re-suspended in an equal volume of the above solution and again homogenized in 10 volumes of desoxycholate $0 \cdot 1 \%$ containing $2 \mathrm{mmol} / 1$ EDTA and $25 \mathrm{mmol} / 1$ Tris- $\mathrm{HCl}$
(pH 7.0). After incubation at $37^{\circ} \mathrm{C}$ for $30 \mathrm{~min}$, the suspension was centrifuged at $25000 \mathrm{~g}$ for $30 \mathrm{~min}$. The pellet was suspended in the above sucrose-EDTA-Tris. This final suspension was frozen at $-20^{\circ} \mathrm{C}$ until assayed.

Assay of ATPase

ATPase activity was determined by the amount of inorganic phosphate $\left(\mathrm{P}_{\mathrm{i}}\right)$ released during incubation at $37^{\circ} \mathrm{C}$ in a shaking, thermostatic bath, as previously described (Gutman et al. 1973). All assays were run in duplicates. The $\mathrm{P}_{\mathrm{i}}$ release was studied in the presence or absence of $\mathrm{K}^{+}$ in the medium. The standard incubation medium consisted of $100 \mathrm{mmol} / 1 \mathrm{NaCl}, 10 \mathrm{mmol} / \mathrm{l} \mathrm{KCl}, 4 \mathrm{mmol} / \mathrm{l}$ $\mathrm{MgCl}_{2}$ and $4 \mathrm{mmol} / \mathrm{l}$ ATP. Enzymatic activity was stopped by the addition of $10 \%$ trichloroacetic acid. $\mathrm{P}_{\mathrm{i}}$ was determined according to the method of Fiske \& Subbarow (1925). Enzymatic protein was assayed according to Lowry et al. (1951). $\mathrm{Na}^{+}-\mathrm{K}^{+}$-ATPase was estimated as the difference of $\mathrm{P}_{\mathrm{i}}$ release with and without $\mathrm{K}^{+}$in the medium.

\section{Metabolic clearance studies}

Sodium and potassium concentrations in serum and urine were determined by flame photometry (Corning 48) and creatinine in blood and urine by automated picric acid method (Cobas-Mira, Hoffman La-Roche, Basel, Switzerland). Urine protein levels were detected automatically by Pyrogallol Red direct colorimetric method in urine and in the same autoanalyser as mentioned above (Cobas-Mira, Hoffman La-Roche).

Plasma glucose was measured using Glucometer Elite (Bayer Corporation, Elkhart, IN, USA) and plasma insulin was measured by radioimmunoassay utilizing antibodies against human insulin (Medgenix, Brussels, Belgium) and human insulin as standard. Dilutions of Psammomys serum gave a curve paralleling those of dilutions of human insulin. Cross-reactivity with purified human insulin used as standard was 90-95\% (Kalderon et al. 1986).

Microsomal renal Na-K-ATPase activity was determined for each animal separately. In the final analysis the results for all animals were combined and expressed as means \pm s.E. for each experimental or control group. Thus the results represent six different determinations added to obtain means \pm S.E. for a given group. Analysis of variance was performed for statistical evaluation between the different groups. Results between individual groups were compared by a non-paired Student's $t$-test with modified levels of significance according to the Bonferroni method (Godfrey 1985).

\section{Results}

\section{Glucose levels}

Blood glucose and insulin levels in fed and fasted state for all groups studied are given in Table 3 . There was no 
Table 3 Blood glucose and plasma insulin levels in fed and fasted state of the Psammomys in all experimental groups

\begin{tabular}{|c|c|c|c|}
\hline & $\begin{array}{l}\text { No. of } \\
\text { animals }\end{array}$ & $\begin{array}{l}\text { Glucose } \\
(\mathrm{mg} / \mathrm{dl})\end{array}$ & $\begin{array}{l}\text { Insulin } \\
(\mu \mathrm{u} / \mathrm{ml})\end{array}$ \\
\hline \multicolumn{4}{|l|}{ Group } \\
\hline \multirow[t]{2}{*}{ Saltbush diet (SB) } & 11 & Fed $86 \pm 3$ & $23 \pm 8$ \\
\hline & & Fast $69 \pm 5$ & $8 \pm 2$ \\
\hline Laboratory artificial diet. & 12 & Fed $89 \pm 4$ & $28 \pm 8$ \\
\hline Low energy (LE) & 25 & Fast $71 \pm 5$ & $9 \pm 2$ \\
\hline High energy diet (HE). & 24 & Fed $351 \pm 13^{*} \ddagger$ & $418 \pm 62 *$ \\
\hline Group C & 10 & Fast $89 \pm 10$ & $60 \pm 8$ \\
\hline High energy diet (HE). & 8 & Fed $437 \pm 10^{*}$ & $92 \pm 15^{*}$ \\
\hline Group D & 10 & Fast $395 \pm 55$ & $28 \pm 9$ \\
\hline High energy diet (HE) & 8 & Fed $425 \pm 8^{*}$ & $318 \pm 61^{*}$ \\
\hline +insulin 2 U/24 h. Group D+I & 12 & Fast $110 \pm 20$ & $320 \pm 40$ \\
\hline
\end{tabular}

${ }^{*} P<0 \cdot 001$ vs groups $\mathrm{SB}$ and $\mathrm{LE} ; \ddagger P<0 \cdot 001$ vs groups $\mathrm{D}$ and $\mathrm{D}+\mathrm{I}$.

Table 4 Biochemical data in normal and diabetic Psammomys

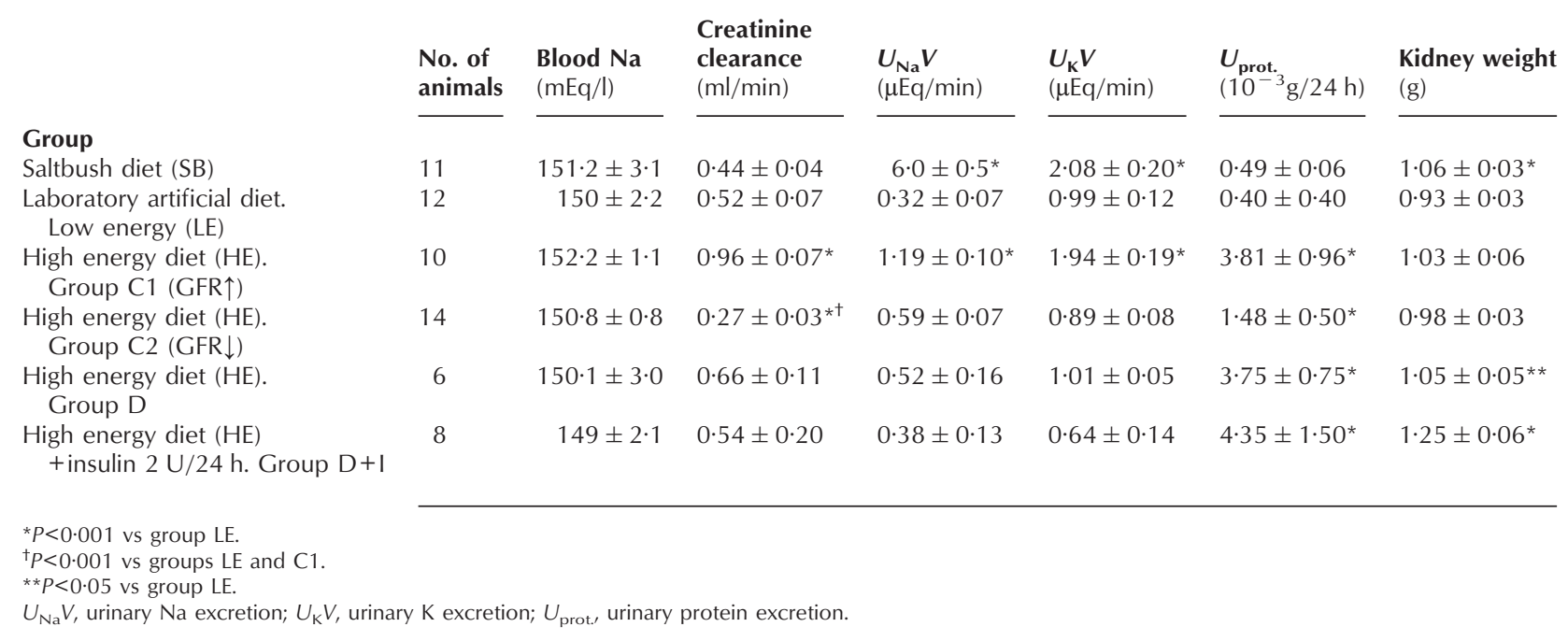

difference in the glucose levels of the Psammomys fed the native, saltbush diet, low energy/high salt diet (SB group) and in those fed low energy/low salt artificial laboratory diet (LE group). The blood glucose levels of the animals in the above two groups at the fed state were less than $140 \mathrm{mg} / \mathrm{dl}$. The glucose level following food intake in the Type II diabetic Psammomys (group C) was high (351 \pm $13 \mathrm{mg} / \mathrm{dl})$.

The Psammomys which developed Type I diabetic state (group D) showed very high blood glucose levels in the fasting state compared with all other groups studied, $395 \pm$ $55 \mathrm{mg} / \mathrm{dl}$, and external insulin supplement reduced it dramatically to $110 \pm 20 \mathrm{mg} / \mathrm{dl}$.

\section{Insulin levels}

The plasma insulin levels were similar in both control groups (low energy/high salt and low energy/low salt diets: SB and LE). The plasma insulin levels were higher in the groups consistent with the diabetic state except for group D in which the hyperglycemia was accompanied with relative hypoinsulinemia. Still, in this group the values of insulin levels were higher compared with the control groups at fed state $(92 \pm 15 \mu \mathrm{U} / \mathrm{ml}$ vs $23 \pm 8$ or $28 \pm 8, P<0 \cdot 001)$.

\section{Kidney function}

Data regarding kidney function are listed in Table 4. The natural saltbush diet (SB) is actually a low energy/high salt diet with a similar caloric content as the low energy/low salt diet (LE) (Table 2). According to the data in Table 4, the animals that were fed on saltbush diet (low energy/ high salt diet) represent the basic natural state of the Psammomys. The results show also that there were no differences between the GFR of saltbush animals (low 
Table 5 Blood $\mathrm{Na}$ levels, GFR, $\mathrm{Na}$ excretion, filtered load of $\mathrm{Na}$ ( $\mathrm{FL}$ of $\mathrm{Na}$ ) and absolute reabsorption of $\mathrm{Na}(\mathrm{AR}$ of $\mathrm{Na}$ ) in normal and diabetic Psammomys

\begin{tabular}{|c|c|c|c|c|c|c|}
\hline & $\begin{array}{l}\text { No. of } \\
\text { animals }\end{array}$ & $\begin{array}{l}\text { Blood Na } \\
(\mathrm{mEq} / \mathrm{l})\end{array}$ & $\begin{array}{l}\text { GFR } \\
(\mathrm{ml} / \mathrm{min})\end{array}$ & $\begin{array}{l}\text { FL of } \mathrm{Na} \\
(\mathrm{mEq} / 24 \mathrm{~h})\end{array}$ & $\begin{array}{l}\text { Na excretion } \\
(\mathrm{mEq} / 24 \mathrm{~h})\end{array}$ & $\begin{array}{l}\text { AR of } \mathrm{Na} \\
(\mathrm{mEq} / 24 \mathrm{~h})\end{array}$ \\
\hline \multicolumn{7}{|l|}{ Group } \\
\hline Saltbush diet (SB) & 11 & $151 \cdot 2 \pm 3 \cdot 1$ & $0 \cdot 44 \pm 0 \cdot 04$ & $95 \cdot 67 \pm 10$ & $8 \cdot 64 \pm 0.9$ & $87 \cdot 03 \pm 10 \cdot 2$ \\
\hline $\begin{array}{l}\text { High energy diet (HE). } \\
\text { Group C1 (GFR } \uparrow)\end{array}$ & 10 & $152 \cdot 2 \pm 1 \cdot 1$ & $0 \cdot 96 \pm 0 \cdot 07$ & $210 \cdot 40 \pm 20^{*}$ & $1 \cdot 71 \pm 0 \cdot 12$ & $208 \cdot 69 \pm 19^{*}$ \\
\hline $\begin{array}{l}\text { High energy diet (HE). } \\
\text { Group D }\end{array}$ & 6 & $150 \cdot 1 \pm 3 \cdot 0$ & $0 \cdot 66 \pm 0 \cdot 11$ & $142 \cdot 60 \pm 7 \cdot 8^{*}$ & $0 \cdot 75 \pm 0 \cdot 15$ & $141 \cdot 85 \pm 8^{*}$ \\
\hline $\begin{array}{l}\text { High energy diet (HE) } \\
\quad+\text { insulin } 2 \mathrm{U} / 24 \text { h. Group } \mathrm{D}+\mathrm{I}\end{array}$ & 8 & $149 \pm 2 \cdot 1$ & $0 \cdot 54 \pm 0 \cdot 20$ & $115 \cdot 86 \pm 11$ & $0 \cdot 55 \pm 0 \cdot 12$ & $115 \cdot 31 \pm 11 \cdot 2$ \\
\hline
\end{tabular}

${ }^{*} P<0 \cdot 05$ vs SB and LE.

energy/high salt diet) and the low energy diet Psammomys (i.e. low energy/low salt diet) which shows that the saltbush diet fed animals handled themselves exactly as the animals on low energy/low salt diet. In the Psammomys fed saltbush (SB) diet, sodium excretion in the urine was 20 times higher compared with that in animals fed the low energy (LE) diet. In the SB fed Psammomys there was also an increase in kidney weight as compared with animals fed laboratory diet. In contrast, the sodium blood levels did not differ between SB diet animals and LE diet Psammomys.

In the early phase of diabetes, usually after the appearance of hyperglycemia, GFR is found to be elevated above that of age-matched normal controls. In established diabetic nephropathy GFR declines progressively and relentlessly towards end-stage renal failure (Viberti et al. 1994).

Accordingly, the Psammomys that were fed HE diet and developed Type II diabetes (group C) were divided into two subgroups consistent with their GFR: (a) group C1 with GFR higher than the control $(0.96 \pm 0.07 \mathrm{ml} / \mathrm{min}$, $P<0 \cdot 001$ vs control LE group), and (b) group C2 with GFR values below that in the control group $(0 \cdot 27 \pm$ $0.03 \mathrm{ml} / \mathrm{min}, P<0.001$ vs control group). In both groups there was a tendency to an increase in kidney weight as compared with animals fed LE diet. The difference, however, did not reach a statistical significance. The diabetic state of these Psammomys was also characterized by an increase in urinary protein excretion as compared with non-diabetic animals $(3 \cdot 81 \pm 0 \cdot 96$ and $1 \cdot 48 \pm 0 \cdot 15$ respectively, $P<0 \cdot 001)$.

In the Psammomys that developed Type I diabetes (group D), there was an increase in kidney weight, in GFR, in sodium excretion and in proteinuria, as compared with the control group.

The Psammomys of group D+I treated with external insulin $(2 \mathrm{U} / 24 \mathrm{~h})$ still showed an increase in kidney weight and proteinuria, but their GFR and sodium excretion decreased to control values, $0 \cdot 54 \pm 0 \cdot 2 \mathrm{ml} / \mathrm{min}$ and $0 \cdot 38 \pm 0 \cdot 13 \mu \mathrm{Eq} / \mathrm{min}$ respectively.
The diabetic kidney is characterized by hyperabsorption of sodium. Table 5 depicts the calculated absolute reabsorption of sodium in the kidney of the different groups studied. In the diabetic animals (group C1) the calculated absolute reabsorption is $208 \pm 19 \mathrm{mEq} / 24 \mathrm{~h}$ and in group D it is $141.8 \pm 8 \mathrm{mEq} / 24 \mathrm{~h}$ and it is high compared with low energy/low sodium (group LE) Psammomys in which absolute $\mathrm{Na}$ reabsorption is $111 \cdot 86 \pm 4 \cdot 9 \mathrm{mEq} / 24 \mathrm{~h}(P<0 \cdot 005$, group LE vs group C1 and group D), see also Table 5 .

\section{Na-K-ATPase activity}

The Na-K-ATPase activity in the cortex and outer medulla in the different experimental groups is depicted in Table 6 and Figs 1 and 2.

The Na-K-ATPase activity was similar in the cortex and medulla of both low energy diet groups: Psammomys fed native saltbush diet and those fed the low energy artificial laboratory diet (groups SB and LE) (Fig. 1).

Table 6 Na-K-ATPase activity of Psammomys in the cortex and medulla in the different diabetic states

\begin{tabular}{|c|c|c|c|}
\hline & $\begin{array}{l}\text { No. of } \\
\text { animals }\end{array}$ & $\begin{array}{l}\text { Cortex } \\
\left(\mu \text { mol } \mathrm{P}_{\mathrm{i}} / \mathrm{mg}\right. \\
\text { prot. per h) }\end{array}$ & $\begin{array}{l}\text { Medulla } \\
\left(\mu \mathrm{mol} \mathrm{P}_{\mathrm{i}} / \mathrm{mg}\right. \\
\text { prot. per h) }\end{array}$ \\
\hline \multicolumn{4}{|l|}{ Group } \\
\hline Salt bush (SB) & 6 & $38 \cdot 7 \pm 8$ & $59 \cdot 7 \pm 5$ \\
\hline LE & 8 & $35 \cdot 9 \pm 3$ & $52 \cdot 5 \pm 5$ \\
\hline C1 & 8 & $72 \cdot 5 \pm 15^{\mathrm{a}}$ & $150 \cdot 8 \pm 16^{c}$ \\
\hline $\mathrm{C} 2$ & 6 & $39 \cdot 8 \pm 5^{\mathrm{e}}$ & $77 \cdot 2 \pm 14^{d}$ \\
\hline $\mathrm{D}$ & 8 & $61 \cdot 9 \pm 8^{a}$ & $158 \cdot 2 \pm 21^{\mathrm{c}}$ \\
\hline$D+1$ & 8 & $39 \cdot 2 \pm 8$ & $94 \cdot 2 \pm 13^{b}$ \\
\hline
\end{tabular}




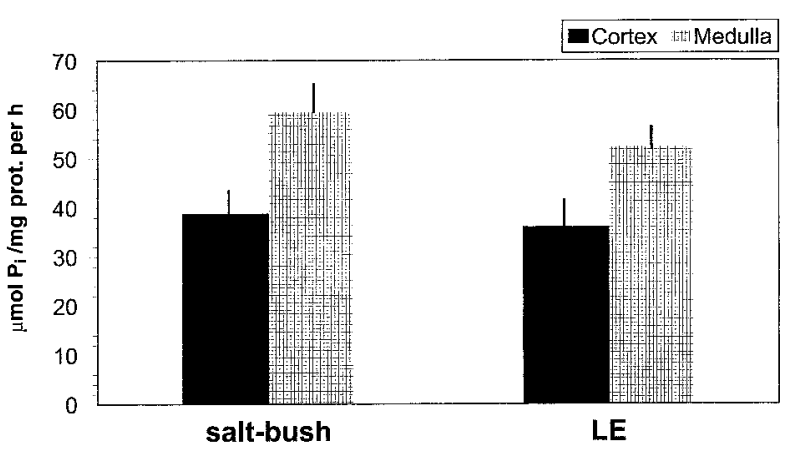

Figure 1 Microsomal Na-K-ATPase activity in renal cortex and medulla of Psammomys on saltbush (low energy/high salt) and on an artificial laboratory (LE) (low energy/low salt) diet. Bars are means \pm S.E.. For saltbush, $n=6$; and for $L E, n=8$. There were no differences in enzyme activity between the two groups, both in the cortex and in the medulla.

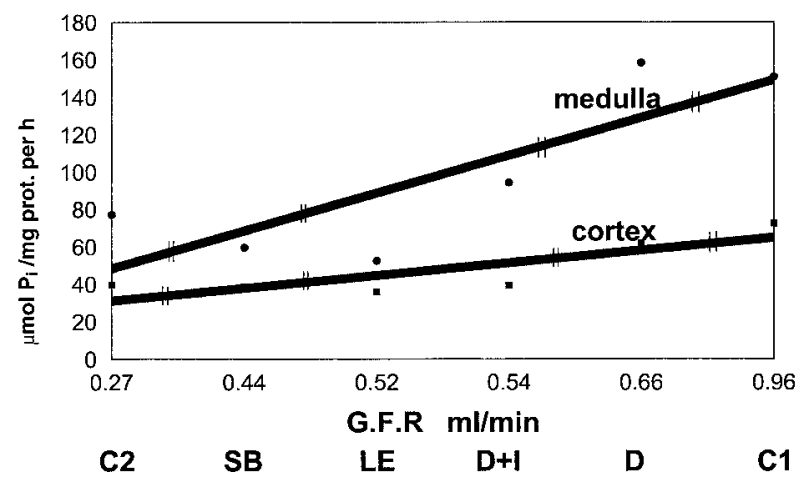

Figure 2 Regression analysis of GFR $(\mathrm{ml} / \mathrm{min})$ with Na-K-ATPase activity ( $\mu \mathrm{mol} \mathrm{P}_{\mathrm{i}} / \mathrm{mg}$ prot. per $\mathrm{h}$ ) in the cortex and the medulla in all groups studied. $\mathbf{\square}$, values for the cortex, $R=0.862, P<0.025$;

- values for the medulla, $R=0 \cdot 798, P<0 \cdot 05$.

Figure 2 represents the regression analysis of GFR with $\mathrm{Na}-\mathrm{K}-\mathrm{ATPase}$ activity in the cortex and medulla in all groups studied. There was an increase in Na-K-ATPase activity in the cortex and the medulla of the Type I (group D) and Type II (group C1) diabetic Psammomys with the high GFR levels, while the enzyme activity in cortex and medulla was decreased towards control values in Psammo$m y s$ with diabetes but lower or normal GFR (groups $\mathrm{C} 2$ and D+I) (Fig. 2, Table 6). The elevation in GFR was associated with a marked increase in $\mathrm{Na}-\mathrm{K}$-ATPase activity of the medulla and, to a lesser extent, of the cortex. The relationship between GFR and $\mathrm{Na}-\mathrm{K}-\mathrm{ATPase}$ activity was statistically significant $(P<0.025$ for the cortex, $P<0 \cdot 05$ for the medulla). This verifies that this relationship is indeed real.

\section{Discussion}

The results of the present study demonstrated similar kidney function (Table 4) and Na-K-ATPase activity
(Table 6, Fig. 1) in Psammomys fed native saltbush (low energy/high salt) and those fed a low energy (LE) laboratory diet (low energy/low salt). In both groups the kidney responded in a similar fashion. Blood glucose, plasma insulin levels, creatinine clearance and urinary protein excretion did not differ between the two groups of Psammomys (Tables 3 and 4). However, as expected, there was a difference between the groups in urine sodium excretion reflecting differences in dietary sodium intake. Thus, the animals fed the laboratory (LE) diet (low energy/low salt) could serve as a control group for all other experimental groups.

In nature Psammomys obtain all their water from their solid food, the saltbush leaves. When transferred to laboratory conditions the transition to the high energy diet leads to the emergence of diabetes mellitus. This abnormality stems, at least partly, from primary insulin resistance and altered physical activity (Ziv et al. 1996).

\section{The effect of diabetes on kidney function}

Psammomys are prone to develop obesity, hyperglycemia and hyperinsulinemia when fed on a high energy diet (Kalman et al. 1993, Ziv \& Shafrir 1995). In our study the Psammomys that developed diabetes on a high energy (HE) diet were subdivided according to their kidney function: (1) group C1 with high creatinine clearance $(0 \cdot 96 \pm$ $0.07 \mathrm{ml} / \mathrm{min}$ ) typical of the early diabetic state in general, and (2) group C2 with low creatinine clearance $(0 \cdot 27 \pm$ $0.03 \mathrm{ml} / \mathrm{min}$ ) similar to diabetic chronic renal disease. The GFR distribution of group C was clearly bimodal. The cut-off point that was selected to divide the groups was a GFR of $0.5 \mathrm{ml} / \mathrm{min}$. Animals with a GFR of less than $0.5 \mathrm{ml} / \mathrm{min}$ were in the low GFR group (C2) and those with a GFR exceeding $0.5 \mathrm{ml} / \mathrm{min}$ were in the high GFR group (C1). Proteinuria was evident in both subgroups (Table 4).

The evolution of diabetic nephropathy in men follows three stages (Viberti et al. 1994). The early stage is characterized by the presence of microalbuminuria and increased GFR. Insulin treatment with adequate metabolic control lowers the GFR almost to normal values (Schmitz et al. 1989). The subsequent stages are characterized by proteinuria above $0.5 \mathrm{~g} /$ day, followed by a decrease in GFR.

The Psammomys with diabetes and high GFR (group C1) represent the early stage of the diabetic kidney (high GFR and proteinuria), while the reduced kidney function of the Psammomys of group C2 (GFR lower than control and the proteinuria higher than control) represents the progression of diabetic nephropathy leading to chronic renal failure.

The present results in group $\mathrm{C} 1$ are compatible with similar findings both in men and experimental animals (Ditzel \& Junken 1972, Morgensen 1972, Gartner 1978). 
The average increment in GFR of group C1 was about $80 \%$ of control values.

Glomerular hyperfiltration is a common finding in clinical and experimental diabetes mellitus as reported by us and others (Morgensen 1972, Canney et al. 1979, Ku \& Meezan 1984, Wald \& Popovtzer 1984, Ku et al. 1986, Khaduri et al. 1987). However, the increase in GFR is poorly understood. In our present experiments, in the Psammomys the differences in GFR were not related to hyperglycemia or to hyperinsulinemia.

Another distinct diabetic subgroup that emerged in this work was characterized by hyperglycemia after fast with hypoinsulinemia (group D). These features are characteristic of Type I diabetes. Treatment with insulin, which lowered blood glucose levels to $110 \pm 20 \mathrm{mg} / \mathrm{dl}$ after fast, corrected most of the metabolic parameters towards normal values including GFR. However, proteinuria and kidney weight remained high.

\section{The relation between $\mathrm{Na}-\mathrm{K}-\mathrm{ATPase}$ and $\mathrm{GFR}$}

No difference was observed in the enzyme activity in the cortex and medulla or in the GFR between the animal groups fed native saltbush diet (SB; low energy/high sodium) and those on low energy laboratory diet (LE; low energy/low sodium) (Fig. 1, Table 4).

In the Psammomys with hyperglycemia and hyperinsulinemia (groups C1 and C2) the enzyme activity corresponded with variations in GFR. Thus, in group C1 with high GFR, the Na-K-ATPase activity was significantly higher both in the cortex and in the medulla as compared with control animals (SB and LE groups), while in group C2, with low GFR, it did not differ from the control animals (Table 6, Fig. 2).

The increase in Na-K-ATPase activity (in cortex and medulla) in diabetic Psammomys with high GFR (group C1) was similar to that which was previously observed in rats with streptozotocin-induced diabetes mellitus (Ku \& Meezan 1984, Wald \& Popovtzer 1984, Ku et al. 1986).

In the Psammomys with fasting hyperglycemia and hypoinsulinemia, that represent Type I diabetes mellitus (group D) with increased GFR $(0.66 \pm 0.11 \mathrm{ml} / \mathrm{min})$, Na-K-ATPase activity was elevated both in the cortex and in the medulla. Insulin treatment in this group (group D+I) reduced GFR towards control values $(0.54 \pm 0.2 \mathrm{ml} / \mathrm{min})$ and accordingly led to a fall in $\mathrm{Na}-\mathrm{K}-\mathrm{ATP}$ ase toward control values in the cortex and in the medulla (Table 6, Fig. 2).

High blood glucose and insulin levels in Psammomys featuring Type II diabetes mellitus (group C2) with a fall in GFR $(0 \cdot 27 \pm 0.03 \mathrm{ml} / \mathrm{min})$ below the levels observed in control group did not affect $\mathrm{Na}-\mathrm{K}-\mathrm{ATP}$ ase, which was similar to that of the control groups.

In groups $\mathrm{C} 1$ and $\mathrm{C} 2$ that were similar with regard to blood glucose and insulin levels, there was a significant difference in the enzyme activity that correlated directly with the variations in GFR. Taken together, these results demonstrate that neither blood glucose control nor plasma insulin levels influence $\mathrm{Na}-\mathrm{K}-\mathrm{ATPase}$ activity in the present experiments.

Glomerular hyperfiltration that was observed in animals with Type II diabetes mellitus (group C1) and Type I diabetes mellitus (group D) was associated with increased $\mathrm{Na}-\mathrm{K}-\mathrm{ATPase}$ activity. By contrast, in Type II diabetes mellitus with diabetic nephropathy (group C2) manifested by reduced GFR, and in animals with diabetes mellitus Type I treated with insulin (group D+I) with normalized blood glucose levels (after fasting) and normalized GFR, Na-K-ATPase activity declined towards control levels (Table 6, Fig. 2).

Figure 2 depicts the regression analysis of GFR with $\mathrm{Na}-\mathrm{K}$-ATPase activity in the cortex and medulla of the different groups studied. An increase in GFR correlated with $\mathrm{Na}-\mathrm{K}$-ATPase activity in the medulla and in the cortex. The relationship between GFR and $\mathrm{Na}-\mathrm{K}-\mathrm{ATP}$ ase activity was statistically significant $(P<0 \cdot 025$ for the cortex, $P<0.05$ for the medulla). This verifies that this relationship is indeed real. These findings are similar to previous observations in rats with streptozotocin-induced diabetes mellitus (Wald \& Popovtzer 1984, Wald et al. 1986, Khaduri et al. 1987). In the rat, Na-K-ATPase activity increased in the cortex and medulla parallel with an increase in GFR.

Our results show that in the different diabetic states in the Psammomys, Na-K-ATPase activity in the cortex and in the medulla are only influenced by GFR levels and not by blood glucose levels and/or plasma insulin levels. The major difference between rats with streptozotocin-induced diabetes mellitus and Psammomys with diabetes mellitus (group D) relates to the effect of hyperglycemia per se (before an increase in GFR occurs) which in rats enhances $\mathrm{Na}-\mathrm{K}-\mathrm{ATP}$ ase activity in the proximal convoluted tubule (PC) and proximal straight tubule (PS), presumably due to stimulated proximal Na-glucose co-transport. This GFRindependent effect was not observed in Psammomys. Thus, the Psammomys resembles the rat with regard to its response to changes in GFR but differs with respect to its response to changes in serum glucose and/or insulin levels. These findings emphasize the importance of species differences in the study of diabetes mellitus.

The increased Na-K-ATPase activity reflects enhanced tubular reabsorption of $\mathrm{Na}$ along the nephron in the early phases of both Type I and Type II diabetes mellitus. Thus, it appears that glomerular hyperfiltration is a common denominator for the rearranged glomerulotubular balance in the diabetic kidney. It has been emphasized that in the diabetic kidney not only hyperfiltration but also hyperabsorption may play an important role in renal insufficiency by causing interstitial inflammations followed by fibrosis. There is a direct relationship between interstitial fibrosis and the degree of renal diseases in general (Schainuck et al. 1970). The Na-K-ATPase activity as 
alluded to before reflects tubular $\mathrm{Na}$ reabsorption and therefore it may be a marker of an increased risk of renal damage. It has been suggested that hyperfiltration is the mechanism for progressive glomerular damage in diabetic nephropathy (Zatz et al. 1985). Therefore, the use of angiotensin converting enzyme (ACE) inhibitors that reduce intraglomerular pressure (Lewis et al. 1993) has been proposed as a protective measure to prevent progressive renal failure. Our findings suggest that the diabetic kidney is not only a hyperfiltering but also a hyperabsorbing organ. Both hyperfiltration and the resulting hyperabsorption, as suggested above, may play an important role in the progression of diabetic nephropathy.

\section{References}

Canney SL, Wong NLM \& Dirks JH 1979 Acute effects of streptozotocin diabetes on rat renal function. Journal of Laboratory and Clinical Medicine 93 950-961.

Degen AA 1988 Ash and electrolyte intakes of the fat sand rat, Psammomys obesus, consuming salt-bush, Atriplex halimus, containing different water content. Physiology and Zoology 61 137-141.

Ditzel J \& Junken K 1972 Abnormal glomerular filtration rate, renal plasma flow, and renal protein excretion in recent and short-term diabetics. British Medical Journal 2 13-19.

Fiske CH \& Subbarow Y 1925 The colorimetric determination of phosphorus. Journal of Biology and Chemistry 66 375-400.

Gartner K 1978 Glomerular hyperfiltration during the onset of diabetes mellitus in two strains of diabetic mice. Diabetologia 15 59-63.

Godfrey K 1985 Comparing the means of several groups. New England Journal of Medicine 313 1450-1456.

Gutman Y, Hochman S \& Wald H 1973 The differential effect of Li on microsomal ATPase in cortex, medulla and papilla of the rat kidney. Biochimica et Biophysica Acta 298 284-290

Jørgensen PL \& Skou JC 1969 Preparation of highly active $\left(\mathrm{Na}^{+}-\mathrm{K}^{+}\right)-$ ATPase from the outer medulla of rabbit kidney. Biochemical and Biophysical Research Communication 37 39-46.

Kalderon B, Gutman A, Levy E \& Shafrir E 1986 Characterization of stages in the development of the obesity-diabetes syndrome in sand rat (Psammomys obesus). Diabetes 35 717-724.

Kalman R, Adler JH, Lazaovici G, Bar-On H \& Ziv E 1993 The efficiency of sand rat metabolism is responsible for development of obesity and diabetes. Journal of Basic Clinical and Physiological Pharmacology 4 57-68.

Katz A \& Epstein FH 1967 The role of sodium potassium-activated adenosine triphosphatase in the reabsorption of sodium by the kidney. Journal of Clinical Investigation 46 1999-2011.

Khaduri C, Barlet-Bas C \& Doucet A 1987 Mechanism of increased tubular Na-K-ATPase during streptozotocin-induced diabetes. Pflugers Archiv 409 296-301.

Ku DD \& Meezan E 1984 Increased renal tubular sodium pump and $\mathrm{Na}-\mathrm{K}$-adenosine triphosphatase in streptozotocin-diabetic rats. Journal of Pharmacology and Experimental Therapeutics 229 664-670.
Ku DD, Sellers BM \& Meezan E 1986 Development of renal hypertrophy and increased renal Na-K-ATPase in streptozotocindiabetic rats. Endocrinology 119 672-677.

Lewis EJ, Hinsicker LG, Bain RP \& Rohde RD 1993 The effect of angiotensin-converting-enzyme inhibition on diabetic nephropathy. New England Journal of Medicine 329 1456-1462.

Lowry OH, Rosebrough NJ, Farr AL \& Randall RJ 1951 Protein measurement with the Folin phenol reagent. Journal of Biological Chemistry 193 265-275.

Morgensen CE 1972 Kidney function and glomerular permeability to macromolecules in juvenile diabetes. Danish Medical Bulletin 19 $1-40$.

Schmidt U \& Dubach UC 1969 Activity of $\left(\mathrm{Na}^{+} \mathrm{K}^{+}\right)$-stimulated adenosintriphosphatase in the rat nephron. Pflügers Archiv 306 219-226.

Schmitz A, Hansen HH \& Christensen T 1989 Kidney function in newly diagnosed Type 2 (non-insulin-dependent) diabetic patients, before and during treatment. Diabetologia 32 434-439.

Schainuck LI, Striker GE, Cutler RE \& Penditt P 1970 Structuralfunctional correlations in renal disease. Part II. The correlations. Human Pathology 1 631-642.

Skou JC 1965 Enzymatic basis for active transport of $\mathrm{Na}^{+}$and $\mathrm{K}^{+}$ across cell membranes. Physiological Review 45 596-617.

Viberti G, Wiseman MJ, Pinto JR \& Messent J 1994 Diabetic nephropathy. In Joslin's Diabetes Mellitus, edn 13, pp 691-714. Eds CR Kahn \& GC Weis. Philadelphia: Lea \& Febiger.

Wald H \& Popovtzer MM 1984 The effect of streptozotocin-induced diabetes mellitus on urinary excretion of sodium and renal Na-KATPase activity. Pflügers Archiv 401 97-100.

Wald H, Epstein FH \& Popovtzer MM 1983 Effect of chronic salt loading on renal Na-K-ATPase activity in the rat. Proceedings of the Society of Experimental Biology and Medicine 172 291-296.

Wald H, Scherzer P \& Popovtzer MM 1986 Enhanced renal tubular ouabain-sensitive ATPase in streptozotocin diabetes mellitus. American Journal of Physiology 251 (Renal Fluid Electrolyte Physiology 20) F164-F170.

Wald H, Scherzer P, Rash R \& Popovtzer MM 1993 Renal tubular $\mathrm{Na}^{+}-\mathrm{K}^{+}$-ATPase in diabetes mellitus: relation to metabolic abnormality. American Journal of Physiology 265 (Endocrinol Metab 28) E96-E101.

Wang PY 1989 Implantable reservoir for supplemental insulin delivery on demand by external compression. Biomaterials 10 197-201.

Zatz R, Meyer TW, Rennke HG \& Brenner BM 1985 Predominance of hemodynamic rather than metabolic factors in the pathogenesis of diabetic nephropathy. PNAS 82 5963-5967.

Ziv E \& Shafrir E 1995 Psammomys obesus: nutritionally induced NIDDM-like syndrome on a 'thrifty gene' background. In Lessons from Animal Diabetes, vol 5, pp 285-300. Ed. E Shafrir. London: Smith-Gordon.

Ziv E, Kalman R, Hershkop K, Barash V, Shafrir E \& Bar-On H 1996 Insulin resistance in NIDDM model Psammomys obesus in the normoglycaemic, normoinsulinaemic state. Diabetologia 39 $1269-1275$.

Received 18 November 1999

Revised manuscript received 21 June 2000

Accepted 17 July 2000 